\title{
The effect of Low Dietary Inflammatory Index score formula on inflammatory, metabolic and clinical outcomes in critically ill Traumatic Brain Injury patients: A Single-blind randomized controlled pilot Study
}

\author{
Sajedeh Jandari ${ }^{1}$, Reza Rezvani ${ }^{1}$, Sajedeh Yousefian ${ }^{2}$, Negin Mosalmanzadeh ${ }^{2}$, Mohammad \\ Bagherniya $^{3}$, Davood Soleimani ${ }^{4}$, Seyedeh Zeynab Mousavian ${ }^{5}$, Nitin Shivappa ${ }^{6}$, JAMES \\ HEBERT $^{6}$, Ali Jafarzadeh Esfahani ${ }^{1}$, Abass Akhgari ${ }^{1}$, Lida Jarahi ${ }^{1}$, and Mohammad \\ Safarian $^{1}$ \\ ${ }^{1}$ Mashhad University of Medical Sciences \\ ${ }^{2}$ Varastegan Institute for Medical Sciences \\ ${ }^{3}$ Isfahan University of Medical Sciences \\ ${ }^{4}$ Kermanshah University of Medical Sciences \\ ${ }^{5}$ Kerman University of Medical Sciences \\ ${ }^{6}$ University of South Carolina Arnold School of Public Health
}

May 28, 2021

\begin{abstract}
Aim: In Traumatic brain injury (TBI) patients, a complex cascade of inflammatory responses is frequently observed following trauma. Numerous dietary agents have long been found to have potential in modulating inflammatory responses. This pilot

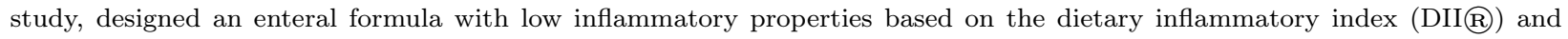
evaluated its effect on inflammatory and metabolic factors in critically ill TBI patients. Methods: This Single-blind randomized controlled pilot study conducted at the Neurosurgical ICU of Shahid Kamyab Hospital (Mashhad, Iran). A total of 20 TBI patients were randomly assigned to receive either low-DII-score or standard formula at the Intensive Care Unit (ICU). The primary outcomes of the study included clinical status, inflammatory biomarkers, APACHE II, SAPS II, SOFA, and NUTRIC scores. Results: The trial groups did not differ significantly on baseline values. Following 14 days of intervention, there was a statistically significant decrease in the APACHE II, SAPS II, and NUTRIC scores and a significant increase in GCS score in the low-DII-score formula group compared to the standard formula group. Over two weeks, high sensitivity c-reactive protein (hs-CRP) values -2.73 (95\% CI: $-3.67,-1.79) \mathrm{mg} / \mathrm{dL}$ in the low-DII-score formula group vs. $0.65(95 \% \mathrm{CI}:-0.29,1.58) \mathrm{mg} / \mathrm{dL}$ in controls. Moreover, the length of hospital stay was longer for the standard formula group than for the low-DII-score formula group. Conclusion: The low-DII-score formula improves inflammatory factors (serum hs-CRP) and metabolic biomarkers (LDL-c and FBS). Furthermore, clinical outcomes, including the length of hospital stay and disease severity appear to be enhanced.
\end{abstract}

\begin{abstract}
:
Aim : In Traumatic brain injury (TBI) patients, a complex cascade of inflammatory responses is frequently observed following trauma. Numerous dietary agents have long been found to have potential in modulating inflammatory responses. This pilot study, designed an enteral formula with low inflammatory properties based on the dietary inflammatory index $\left(\mathrm{DII}{ }^{\circledR}\right)$ and evaluated its effect on inflammatory and metabolic factors in critically ill TBI patients.
\end{abstract}


Methods : This Single-blind randomized controlled pilot study conducted at the Neurosurgical ICU of Shahid Kamyab Hospital (Mashhad, Iran). A total of 20 TBI patients were randomly assigned to receive either low-DII-score or standard formula at the Intensive Care Unit (ICU). The primary outcomes of the study included clinical status, inflammatory biomarkers, APACHE II, SAPS II, SOFA, and NUTRIC scores.

Results : The trial groups did not differ significantly on baseline values. Following 14 days of intervention, there was a statistically significant decrease in the APACHE II, SAPS II, and NUTRIC scores and a significant increase in GCS score in the low-DII-score formula group compared to the standard formula group. Over two weeks, high sensitivity c-reactive protein (hs-CRP) values -2.73 (95\% CI: -3.67, -1.79) $\mathrm{mg} / \mathrm{dL}$ in the lowDII-score formula group vs. 0.65 (95\% CI: $-0.29,1.58) \mathrm{mg} / \mathrm{dL}$ in controls. Moreover, the length of hospital stay was longer for the standard formula group than for the low-DII-score formula group.

Conclusion : The low-DII-score formula improves inflammatory factors (serum hs-CRP) and metabolic biomarkers (LDL-c and FBS). Furthermore, clinical outcomes, including the length of hospital stay and disease severity appear to be enhanced.

Keywords: dietary inflammatory index, traumatic brain injury, enteral nutrition, inflammation, formula

\section{What is already known about this topic?}

Nutritional support is defined as the prescription of formulated enteral or parenteral nutrients to the patients who cannot meet their nutritional requirements through normal diets in order to maintain and enhance their nutritional status. In the late 1970s, EN support was in its infancy, and only 16 enteral formulas were available. Within the past few decades, these formulas have increased dramatically. As such, selecting the most appropriate formula is rather challenging considering the wide array of the available formulas. However, only a few prospective, randomized, controlled interventions support the claimed indications for the specific formulas that are currently available on the market. In the past two decades, numerous clinical studies have investigated the role of antioxidant micronutrients in the form of monotherapy or polytherapy in the mortality and clinical outcomes of critically ill patients. Accordingly, pharmaconutrition and immunomodulatory formulas have beneficial effects, which are associated with the negative regulation of pro-inflammatory responses in patients with trauma, sepsis, and other inflammatory injuries. Nevertheless, evidence regarding the benefits of these formulas remains controversial .

\section{What does this article add?}

In contrast with other formulas with high antioxidant agents our formula has been focused on the formulation of antioxidant and anti-inflammatory nutrients in terms of their dietary inflammation indices (DII). Specific amounts of some vitamins (includes vitamin A, B1, B2, B3, B5, B6, B9, C, D3) minerals (Mg, Se, Zn), and two pharmaco-nutrients (saffron and turmeric) with a negative inflammatory index score which have anti-inflammatory properties were considered. Of note, the amount of these additional nutrients in the new formula was considered between the amount of the recommended daily allowance (RDA) and the upper limit (UL) of intake. This pilot study aimed to assess the effects of this low-DII score enteral formula on metabolic, inflammatory factors and clinical outcomes of patients admitted to intensive care units (ICU).

It should be mentioned that our formula has been registered and approved as a national patent in Iran (patent number: 102502).

Clinical Relevancy Statement: Acute inflammation can be caused by an initial immune response to trauma, injury, and burn, and it can affect the body metabolism including the nutritional need and nutrient uptake. Diet can affect the body by various mechanisms such as reducing inflammatory processes, increasing levels of antioxidants, altering lipid profiles, and altering the microbial balance of the intestine. By understanding the complications of inflammatory and catabolic conditions in critically ill patients, we decided to design a new low dietary inflammatory index (DII) formula to reduce inflammatory markers in patients admitted to intensive care units (ICU).

\section{Introduction}


Traumatic brain injury (TBI) remains a challenging issue in critical care medicine due to its contribution to the majority of trauma-related deaths (1-3). TBI refers to non-congenital brain injury, initiated with focal or diffuse lesions at the time of the primary injury and possibly prolonged and exacerbated by a set of complex systemic and local events that results in secondary brain injury (4). The secondary injury is found to be promoted by several diverse etiologies, including metabolic changes, inflammation, ischemia, oedema, and excitotoxicity (5).

In the last two decades, investigators have made great progress in understanding the main mechanistic pathways linking inflammation to secondary brain injury after trauma (6). Post-traumatic neuroinflammation, the neurogenic inflammation following TBI, is primarily developed by several extracellular and intracellular signalling pathways and is found to be a key contributor to secondary injuries $(4,7)$. TBI also initiates systemic inflammatory response syndrome (SIRS), which is found to be a potential factor in raising the risk of nosocomial infection or multiple organ dysfunction (MOD) (8). SIRS score potentially predicts the length of hospital stay (LOS) and patients' mortality (9). In the Intensive Care Unit (ICU), critically ill patients receive some supportive care, including nutritional support and mobilization in order to restore or maintain organ function. In critically ill TBI patients, early nutritional support via enteral route is of particular interest due to the enhanced neurological recovery, shortened LOS, and reduced mortality $(10,11)$.

Multiple lines of evidence have illustrated a direct correlation between certain dietary agents and reduced levels of inflammatory markers $(12,13)$. More specifically, providing ICU patients with immune-modulating nutrients (e.g., antioxidants, omega-3 fatty acids, glutamine, and arginine) not only prevents malnutrition, but also results in favourable alterations in inflammatory components, lipid profiles, antioxidant levels, intestinal microbial balance, and their acquired immune function (14-16). However, there is a scarcity of clinical knowledge about assessing the effect of antioxidant-rich enteral formulas on the clinical and biochemical outcomes of ICU patients. The Dietary inflammatory index $\left(\mathrm{DII}{ }^{\circledR}\right)$ is a literature-derived tool, specifically developed to evaluate the inflammatory potential of food components on inflammatory biomarkers, such as C-reactive protein (CRP) (17). To our knowledge, there is no intervention study based on the DII score in critically ill TBI patients. Given that and due to the paucity of data on the effect of the DII score on metabolic and inflammatory responses in critically ill patients, this pilot study aimed to assess the effects of a low DII score enteral formula on metabolic and inflammatory factors of TBI patients admitted to ICU.

\section{2- Materials and methods:}

\section{2-1 Study design}

This single-centre, prospective, randomized, single-blind, controlled clinical trial was conducted on 20 patients with TBI admitted to the neurosurgical ICU of Shahid Kamyab Hospital (Mashhad, Iran) from October 2018 to August 2019. The study was retrospectively registered in the Iranian Registry of Clinical Trials (IRCT; registry number: IRCT20180515039674N1). The study protocol (18) was approved by the Research Ethics Committee of Mashhad University of Medical Sciences, Mashhad, Iran (reference approval number: IR.MUMS.REC.1397.149).

\section{2-2 Patients and variables}

Twenty TBI patients (18-65 years) with clinical manifestations indicative of poor prognosis were enrolled in this study. Data collected included the diagnosis upon ICU admission, demographic information, and medical history. Informed consent was obtained from all the patients or their legal representatives. The inclusion criteria were: age between 18-65 years, moderate or severe trauma (GCS index 4-14), having normal-functioning gastrointestinal tract and indications of EN. The eligible patients were enrolled within 24-48 hours after ICU admission. The exclusion criteria were: failure to start EN within the first 48 hours of admission, any history of underlying diseases (including heart disease, diabetes, congenital and immunological disorders, renal and hepatic failure, pancreatitis) receiving multiple transfusion, enteral feeding intolerance, and less than 96 hours ICU LOS. Patients with body mass index (BMI) $<18.5 \mathrm{Kg} / \mathrm{m}^{2}$, and patients who received total parenteral nutrition also were excluded from the study. 


\section{2-3 Randomization and Blinding}

The study group's randomization was carried out by the first author based on the inclusion and exclusion criteria. The patients were stratified upon randomization based on their age (18-65 years), gender, and disease severity based on the acute physiology and chronic health evaluation (APACHE) II score in order to ensure the equal distribution of these variables in both groups. Due to the difference in the colours of the intervention and traditional formulas in this study, the physician and nurses could not be blinded regarding patient allocation. In contrast, the patients and outcome evaluators were blinded, and the investigator was not directly involved in the intervention process and patients' care. Laboratory personnel, pathologists, and statisticians also were blinded to the treatment allocation.

\section{2-4 Study measurements}

Demographic data, the severity of the condition, inflammatory factors and blood chemistry were assessed for all patients. The severity of the condition was assessed using the Acute Physiology and Chronic Health Evaluation (APACHE II) scoring system, sequential organ failure assessment (SOFA) Scoring system and the Simplified Acute Physiology Score (SAPS) II. The levels of inflammatory factors were evaluated by measuring hs-CRP and TNF- $\alpha$ using Elisa tests. Nutritional status was assessed using the nutrition risk in critically ill (NUTRIC) score and by measuring BMI, mid-arm circumference. Lipid profile, including triglyceride (TG), total cholesterol, high-density lipoprotein (HDL) and low-density lipoprotein (LDL) cholesterol, fasting blood sugar (FBS) were also measured. Furthermore, liver function test, including aspartate aminotransferase (AST), alanine aminotransferase (ALT), alkaline phosphatase (ALP) and total and direct bilirubin were also assessed for each patient. Kidney function tests, including blood urea and creatinine, were also assessed.

\section{2-5 Procedures}

\section{Phase 1: low-DII-score formula}

In order to design a new formula with anti-inflammatory properties, the Karen Pharma and Food Supplement Co. (PNC) standard EnteraMeal formula was fortified based on the DII score of nutrients. Specific amounts of some vitamins (includes vitamin $\left.\mathrm{A}, \mathrm{B}_{1}, \mathrm{~B}_{2}, \mathrm{~B}_{3}, \mathrm{~B}_{5}, \mathrm{~B}_{6}, \mathrm{~B}_{9}, \mathrm{C}, \mathrm{D}_{3}\right)$ minerals $(\mathrm{Mg}, \mathrm{Se}, \mathrm{Zn}$ ), and two pharmaco-nutrients (saffron and turmeric) with a negative inflammatory index score which have antiinflammatory properties were considered. Of note, the amount of these additional nutrients in the new formula was considered between the amount of the recommended daily allowance (RDA) and the upper limit (UL) of intake. In this way, not only is the patient's RDA provided via an average daily intake of 2000 cc formulation powder, but the person's inflammatory status improves without exceeding the UL. After consulting with the pharmaceutics advisory professors, a new formulation was designed and sent to James R. Hebert and Nitin Shivappa (advisory professors in the field of DII) for approval. The nutrient content of the formula is presented in Table 1. The sources and kinds of added nutrients are mentioned in Table 2.

\section{Phase 2: Intervention Process}

The patients were selected via non-probability purposive sampling based on the inclusion and exclusion criteria within 24-48 hours after admission to the ICU, matched in terms of age, gender, type of lesions, GCS score, and type of lesions, and randomly divided into two groups. Data were collected using observational laboratory methods. Two treatment modalities were implemented after obtaining the demographic data (age, gender, diagnosis upon admission, and classification of hospitalization). Among the other collected data was personal information of the patients, medicinal and medical history, and informed consent was obtained from the patients or their legal representatives. Following that, the patients were randomly divided into two groups of control and intervention. Hemodynamic resuscitation and stabilization were carried out within the first 24-48 hours of admission. Afterwards, EN was initiated to provide $80-100 \%$ of the energy requirements of the patients ( $25 \mathrm{kcal} / \mathrm{kg}$ body weight). The amount of formula required for each patient was determined individually, and the treatment commenced within the first 24-48 hours of hospitalization (seven times per every 24 hours). The intervention continued for 14 days. Blood sampling was performed after the last gavage meal at night, similarly in both groups on days zero, 7 and 14 (figure-1). 


\section{2-6 Statistical analysis}

The statistical package for social sciences (SPSS) software for Windows version 18 (IBM Inc., Chicago, IL, USA) was used for data analysis. Between-group comparison of nominal or the categorical variables was ascertained with the use of chi-square test or Fisher's exact test. After determining normality using the Shapiro-Wilk test, the between-group comparison of continuous variables was ascertained using independent sample T or Mann-Whitney U Test (non-normal distribution). Analysis of covariance (ANCOVA) test was used to determine the mean change and effect size with the adjustment for sex and age. P-value $<0.05$ was considered statistically significant.

\section{3- Results}

The statistical package for social sciences (SPSS) software for Windows version 18 (IBM Inc., Chicago, IL, USA) was used for data analysis. Between-group comparison of nominal or the categorical variables was ascertained with the use of chi-square test or Fisher's exact test. After determining normality using the Shapiro-Wilk test, the between-group comparison of continuous variables was ascertained using independent sample T or Mann-Whitney U Test (non-normal distribution). Analysis of covariance (ANCOVA) test was used to determine the mean change and effect size with the adjustment for sex and age. P-value $<0.05$ was considered statistically significant.

A total of 67 consecutive patients with TBI were admitted to the ICU from October 2018 to August 2019; twenty patients met all eligibility criteria and then underwent randomization and were followed until hospital discharge. All patients received either standard or anti-inflammatory formula for 14 days. The trial groups were well matched in terms of demographic characteristics. The majority of patients were male, all patients in the intervention group and 8 of the control group (P-value: 0.47$)$. The mean $( \pm \mathrm{SD})$ age and weight were $36.40 \pm 18.72$ and $38.50 \pm 16.83$ years and $76.30 \pm 6.06$ and $73.50 \pm 11.27 \mathrm{~kg}$ in the intervention and control group, respectively. In each trial group, $30 \%$ and $20 \%$ of participants had subarachnoid and intracranial haemorrhage, respectively. Subdural haemorrhage was present in $30 \%$ of the control group but in only $20 \%$ of the intervention group and other participants had contusion (P-value: 0.30 ). The comparison of the clinical, nutritional, and laboratory characteristics at the baseline showed no significant differences between the trial groups (Table 3,4).

The mean of total calorie intake during the 7 and 14 days of the intervention was $8295 \pm 1567$ and $18655 \pm$ $2976 \mathrm{Kcal}$ in the intervention group and $8615 \pm 1583$ and $19115 \pm 2118 \mathrm{Kcal}$ in the control groups, respectively. The trial groups did not differ significantly in terms of energy intake. Adjusted mean changes (95\% CI) in laboratory characteristics from baseline to 7- and 14-day intervention are summarized in Table 5. Serum TC concentration and PLT count increased significantly, whereas serum hs-CRP and creatinine concentrations and WBC count decreased significantly in the intervention group during the first week of the intervention. The serum BUN, LDL-c, and TC concentrations and PLT count during the first week of the intervention increased significantly in the control group. Other parameters did not significantly change in either group during this period. The two groups did not differ significantly with respect to laboratory parameters within the first week of intervention. The serum hs-CRP and FBS concentrations and PLT and WBC count in the intervention group and the serum TNF- $\alpha$, FBS, LDL-c, and creatinine concentrations and PLT count in the control group changed significantly from baseline to 14-day intervention. Other parameters did not significantly change in either group during this period. Among these variables, only hs-CRP, FBS, and LDL-c showed a significant reduction in the intervention group compared with the control group.

Multivariable-adjusted mean changes (95\% CI) in clinical characteristics are summarized in Figure 2. Withingroup comparisons showed that only MAC decreased significantly in both groups and GCS scores increased significantly in the intervention group during the first 7 days of the intervention. The between-group comparison demonstrated that only the average increase in GCS score was significantly higher in the intervention group compared to the control group during this period $(\mathrm{P}$ value $=0.032)$. The mean of APACHE II and SAPS II scores and MAC during the 14 days of the intervention decreased and GCS increased significantly in the intervention group. On the other hand, in the control group, MAC decreased and NUTRIC scores 
increased significantly. The comparison of the changes in clinical parameters between the study groups following 14 days of intervention demonstrated that the average change in GCS score was significantly higher and also change in APACHE II, SAPS II, and NUTRIC scores were significantly lower in the intervention group compared with the control group. Moreover, the adjusted mean $(95 \% \mathrm{CI})$ for hospital length of stay (LOS) was $73.21(55,91.4)$ days for the control group and $41.99(23.80,60.18)$ days for the intervention group (Figure3).

\section{Discussion}

The overall results indicated that designing an enteral formula with a low DII score for critically ill patients is associated with a significantly greater reduction in serum hs-CRP, LDL-c, and FBS levels compared to the group receiving standard formula. On the other hand, the average change in GCS score was significantly higher, and changes in APACHE II, SAPS II, and NUTRIC scores were significantly lower in the intervention group compared to the control group. Moreover, the intervention group had a significantly shorter LOS compared to the control group.

Our results demonstrated that although hs-CRP levels did not differ significantly between the two groups on day 7 , it was statistically significant on day 14 . Additionally, the hs-CRP decrease trend was statistically significant in the intervention group, while no significant changes were observed in the control group. This is in line with previous findings, demonstrating a significant positive relationship between DII and several inflammatory biomarkers, including IL-6 (19, 20) and hs-CRP concentration(19). CRP is a non-specific biomarker reflecting any inflammatory condition that commonly increases 4-6 hours after trauma or surgery (21). The declining trend in hs-CRP levels indicate the patient's entry into the anabolic phase; at this point, nutritional intervention can be effective (17). The hs-CRP test is widely used to accurately measure the low levels of CRP and diagnose vascular inflammation (22). In a Lothian Birth cohort study, Corley et al. investigated the association between the energy-adjusted DII score (derived from food-frequency questionnaires) with the serum level of hs-CRP. Their result indicated that DII/E-DII, as a valid index, has the ability to estimate inflammatory markers, and diet seems to play an important role in regulating the inflammatory conditions in the body (23). On closer inspection, inflammatory biomarkers such as TNF-a and IL-1 have several common pro-inflammatory properties, such as prostaglandin E2 (PGE2) production as well as the activation of collagenase (24), which in cases such as rheumatoid arthritis can cause joint damage. Vitamins and minerals can affect cyclooxygenase and lipoxygenase pathways, modulate the production of prostaglandins such as PGE2, and thereby alter the response to injuries and infections (25).

Recently, this effect has been studied especially in patients with malnutrition and it was observed that diets rich in n-3 fatty acids, arginine, glutamine, and vitamins $\mathrm{C}$ and $\mathrm{E}$ improve clinical outcomes including infections, inflammation, and complications occur in patients after surgery or trauma. $(26,27)$. In accordance with previous literature, our enriched low-DII formula with anti-inflammatory properties may affect this process in critically ill patients by increasing the intake of dietary antioxidants.

The present study also suggested that LDL-c levels in the group receiving low-DII-score formula decrease significantly compared to the group receiving standard formula. Previous studies have proposed the mechanisms underlying inflammation-related alterations in lipid metabolism, leading to increased levels of LDL-c, lipoprotein (a), and triglycerides and decreased HDL levels (28). A recent study conducted by Phillips et al. Found that diets with higher DII scores (more pro-inflammatory diet) caused unfavourable alterations in lipid profile, including elevated LDL-c levels (29). Moreover, Ridker et al. found that the higher levels of hs-CRP are significantly associated with items of metabolic syndrome including hypertriglyceridemia, Low HDL-level, obesity, hypertension and abnormal glucose metabolism (22). These findings are consistent with another study conducted by Vahid et al. on 400 patients using a food frequency questionnaire. In that study, they determined the inflammatory index of individuals' diet and found that subjects in the third tertile of DII had significantly higher levels of FBS, HbA1C, LDL, TG, and body fat, but lower levels of HDL. Their results also showed that those who consumed a more pro-inflammatory diet were at higher risk for prediabetes (30). Decades ago, Scientists found that inflammation exacerbates insulin resistance, which can eventually lead to higher FBS levels (31). Hyperglycemia is probably a sign of an active inflammatory 
response that is accompanied by an increase in tumour necrosis factor (TNF) activated by nuclear factor kappa b (NF- $\beta$ ). Hyperglycemia can also increase the production of reactive oxygen or nitrogen species and counteracts insulin activity in the human body (32). This pathway explains the significant decrease in FBS levels in the intervention group compared to the control group in our study.

Regarding clinical parameters, the GCS score, as a scoring system for assessing the TBI severity, was significantly higher in the intervention group than in the control group. Previous studies have shown that the lower the score of GCS in TBI patients, the higher unfavourable outcomes following trauma and mortality tend to be $(33,34)$ Traumatic brain injury may cause severe brain inflammation, resulting in cerebral oedema and elevated intracranial pressure. This condition can worsen the GCS score (35); therefore, reducing inflammation can help to maintain GCS. Inflammation in critically ill patients is characterized by major alterations in energy, macronutrients and micronutrients requirements, as well as changes in metabolism and reduced nutrient absorption. These destructive processes ultimately increase the risk of malnutrition in critically ill patients admitted to the ICU (36). The NUTRIC score, a new screening tool assessing patients' nutritional risk (37), was found to be significantly higher in the group received low DII formula than the control group on day 14. The three prognostic indices, APACHE II, SOFA, and SAPS II scores, are highly regarded in clinical assessments due to the use of multiple physiological variables (38). According to our results, the APACHE II score did not differ significantly between the intervention and control groups at baseline and day 7. On day 14, however, this score was significantly lower in the intervention group compared to the control group. On the other hand, the trend of the SAPS II scores in the intervention group was significantly downward throughout the long-term intervention period, while this trend was upward in the control group. Moreover, a significant difference was found between the two groups. In a retrospective cohort study, Basil et al. examined the prognostic indices (APACHE II, SOFA and SAPS 3) as well as biological markers (hs-CRP/Albumin and lactate) in 765 patients to predict the mortality rate of surgical patients admitted to the ICU. They found out that prognostic indices such as APACHE II, APACHE DP (APACHE death probability), SAPS 3, and SAPS 3 DP (SAPS 3 death probability) have greater predictability than biological markers such as lactate, albumin, CRP and CRP/albumin in patients' mortality admitted to the ICU (39).

Mean hospital LOS in the intervention group was significantly lower than the control group. This is consistent with our other findings on reducing the level of inflammation and the severity of the disease in ICU. Similarly, a study of 193 patients who underwent colorectal surgery found that lower hs-CRP levels on the second postoperative day (POD2) were associated with a shorter hospital LOS (40).

In the present study, a homogeneous group of TBI patients was enrolled, which adjusted the impact of confounding variables in both study groups. Patients were carefully and regularly monitored by recording nutritional intake and clinical testing, a major advantage over more poorly controlled studies. In the present pilot study, although the sample size was calculated based on the study of Lee et al. (41), a larger sample size would have increased precision. In this study, the samples were obtained from a single hospital. With these encouraging results as background, future multi-centre studies should be planned to obtain more robust results. Moreover, it might be advisable to extend follow-up for longer periods of time.

\section{Conclusions}

This study demonstrated that low-DII-score formula (which contains vitamins, salts and nutrients with anti-oxidant properties) may improve inflammatory factors (hs-CRP), metabolic biomarkers, and clinical outcomes in critically ill TBI patients admitted in the intensive care unit. However, despite the important clinical results of the present study, it seems that the formula used in this study needs to be evaluated in larger patient groups and multi-centre trials in order to produce more robust and generalizable results, that can help guide clinical practice.

\section{References}

1. Rusnak M. Traumatic brain injury: Giving voice to a silent epidemic. Nature Reviews Neurology. $2013 ; 9(4): 186$. 
2. Baker CC, Oppenheimer L, Stephens B, Lewis FR, Trunkey DD. Epidemiology of trauma deaths. The American Journal of Surgery. 1980;140(1):144-50.

3. Shackford SR, Mackersie RC, Holbrook TL, Davis JW, Hollingsworth-Fridlund P, Hoyt DB, et al. The epidemiology of traumatic death: a population-based analysis. Archives of surgery. 1993;128(5):571-5.

4. Prasetyo E. The primary, secondary, and tertiary brain injury. Critical Care and Shock. 2020;23:4-13.

5. Algattas H, Huang JH. Traumatic brain injury pathophysiology and treatments: early, intermediate, and late phases post-injury. International journal of molecular sciences. 2014;15(1):309-41.

6. Lenzlinger PM, Morganti-Kossmann M-C, Laurer HL, McIntosh TK. The duality of the inflammatory response to traumatic brain injury. Molecular neurobiology. 2001;24(1-3):169-81.

7. Wofford KL, Loane DJ, Cullen DK. Acute drivers of neuroinflammation in traumatic brain injury. Neural regeneration research. 2019;14(9):1481.

8. Simon DW, McGeachy MJ, Bayır H, Clark RS, Loane DJ, Kochanek PM. The far-reaching scope of neuroinflammation after traumatic brain injury. Nature Reviews Neurology. 2017;13(3):171.

9. Jacome T, Tatum D. Systemic inflammatory response syndrome (SIRS) score independently predicts poor outcome in isolated traumatic brain injury. Neurocritical care. 2018;28(1):110-6.

10. Sacks GS, Brown RO, Teague D, Dickerson RN, Tolley EA, Kudsk KA. Early nutrition support modifies immune function in patients sustaining severe head injury. Journal of Parenteral and Enteral Nutrition. 1995;19(5):387-92.

11. Härtl R, Gerber LM, Ni Q, Ghajar J. Effect of early nutrition on deaths due to severe traumatic brain injury. Journal of neurosurgery. 2008;109(1):50-6.

12. Dibaba DT, Xun P, He K. Dietary magnesium intake is inversely associated with serum C-reactive protein levels: meta-analysis and systematic review. European journal of clinical nutrition. 2014;68(4):510-6.

13. Ramezani A, Yousefinejad A, Javanbakht MH, Derakhshanian H, Tahbaz F. Effect of beta-carotene enriched carrot juice on inflammatory status and fasting blood glucose in type 2 diabetic patients. Current Topics in Nutraceuticals Research. 2014;12(1/2):1.

14. Calder PC. n- 3 Fatty acids, inflammation, and immunity - Relevance to postsurgical and critically III patients. Lipids. 2004;39(12):1147-61.

15. Hegazi RA, Wischmeyer PE. Clinical review: optimizing enteral nutrition for critically ill patients-a simple data-driven formula. Critical Care. 2011;15(6):234.

16. Hagen KB, Byfuglien MG, Falzon L, Olsen SU, Smedslund G. Dietary interventions for rheumatoid arthritis. Cochrane Database of Systematic Reviews. 2009(1).

17. Shivappa N, Steck SE, Hurley TG, Hussey JR, Ma Y, Ockene IS, et al. A population-based dietary inflammatory index predicts levels of C-reactive protein in the Seasonal Variation of Blood Cholesterol Study (SEASONS). Public health nutrition. 2014;17(8):1825-33.

18. Jandari S, Rezvani R, Mosalmanzadeh N, Ranjbar G, Yousefian S, Shadmand Foumani Moghadam $\mathrm{MR}$, et al. The Effects of Low Dietary Inflammatory Index Formula on the Inflammatory and Metabolic Biomarkers of Patients with Multiple Traumas in Intensive Care Units: A Study Protocol for a Single-blind, Randomized, Controlled Trial. Journal of Nutrition, Fasting and Health.9(1).

19. Shivappa N, Steck SE, Hurley TG, Hussey JR, Ma Y, Ockene IS, et al. A population-based dietary inflammatory index predicts levels of C-reactive protein in the Seasonal Variation of Blood Cholesterol Study (SEASONS). Public health nutrition. 2014;17(8):1825-33. Epub 2013/10/11. doi: 10.1017/s1368980013002565. PubMed PMID: 24107546; PubMed Central PMCID: PMCPmc3983179. 
20. Shivappa N, Hebert JR, Rietzschel ER, De Buyzere ML, Langlois M, Debruyne E, et al. Associations between dietary inflammatory index and inflammatory markers in the Asklepios Study. British Journal of Nutrition. 2015;113(4):665-71.

21. Vincent J-L, Donadello K, Schmit X. Biomarkers in the critically ill patient: C-reactive protein. Critical care clinics. 2011;27(2):241-51.

22. Ridker PM, Glynn RJ, Hennekens CH. C-reactive protein adds to the predictive value of total and HDL cholesterol in determining risk of first myocardial infarction. Circulation. 1998;97(20):2007-11.

23. Corley J, Shivappa N, Hebert J, Starr J, Deary I. Associations between dietary inflammatory index scores and inflammatory biomarkers among older adults in the Lothian birth cohort 1936 study. The journal of nutrition, health \& aging. 2019;23(7):628-36.

24. Feghali CA, Wright TM. Cytokines in acute and chronic inflammation. Front Biosci. 1997;2(1):d12-d26.

25. Mahan LK, Raymond JL. Krause's food \& the nutrition care process-e-book: Elsevier Health Sciences; 2016 .

26. Marano L, Porfidia R, Pezzella M, Grassia M, Petrillo M, Esposito G, et al. Clinical and immunological impact of early postoperative enteral immunonutrition after total gastrectomy in gastric cancer patients: a prospective randomized study. Annals of surgical oncology. 2013;20(12):3912-8.

27. Klek S, Sierzega M, Szybinski P, Szczepanek K, Scislo L, Walewska E, et al. Perioperative nutrition in malnourished surgical cancer patients-a prospective, randomized, controlled clinical trial. Clinical nutrition. 2011;30(6):708-13.

28. Khovidhunkit W, Kim M-S, Memon RA, Shigenaga JK, Moser AH, Feingold KR, et al. Effects of infection and inflammation on lipid and lipoprotein metabolism: mechanisms and consequences to the host. The Journal of Lipid Research. 2004;45(7):1169-96.

29. Phillips CM, Shivappa N, Hebert JR, Perry IJ. Dietary inflammatory index and biomarkers of lipoprotein metabolism, inflammation and glucose homeostasis in adults. Nutrients. 2018;10(8):1033.

30. Vahid F, Shivappa N, Karamati M, Naeini AJ, Hebert JR, Davoodi SH. Association between Dietary Inflammatory Index (DII) and risk of prediabetes: a case-control study. Applied Physiology, Nutrition, and Metabolism. 2017;42(4):399-404.

31. Wellen KE, Hotamisligil GS. Inflammation, stress, and diabetes. The Journal of clinical investigation. 2005;115(5):1111-9.

32. Langouche L, Vanhorebeek I, Vlasselaers D, Vander Perre S, Wouters PJ, Skogstrand K, et al. Intensive insulin therapy protects the endothelium of critically ill patients. The Journal of clinical investigation. 2005;115(8):2277-86.

33. McIntyre A, Mehta S, Aubut J, Dijkers M, Teasell RW. Mortality among older adults after a traumatic brain injury: a meta-analysis. Brain injury. 2013;27(1):31-40.

34. Gilani N, Kazemnejad A, Zayeri F, ASGHARI JM, IZADI AFS. Predicting outcomes in traumatic brain injury using the glasgow coma scale: A joint modeling of longitudinal measurements and time to event. 2017.

35. Strauss KI. Antiinflammatory and neuroprotective actions of COX2 inhibitors in the injured brain. Brain, behavior, and immunity. 2008;22(3):285-98.

36. Ndahimana D, Kim E-K. Energy requirements in critically ill patients. Clinical nutrition research. $2018 ; 7(2): 81-90$. 
37. Heyland DK, Dhaliwal R, Jiang X, Day AG. Identifying critically ill patients who benefit the most from nutrition therapy: the development and initial validation of a novel risk assessment tool. Critical Care. 2011;15(6):R268.

38. Lewandowski K, Lewandowski M. Scoring systems in the intensive care unit. Der Anaesthesist. 2003;52(10):965-87; quiz 88-9.

39. Basile-Filho A, Lago AF, Menegheti MG, Nicolini EA, de Brito Rodrigues LA, Nunes RS, et al. The use of APACHE II, SOFA, SAPS 3, C-reactive protein/albumin ratio, and lactate to predict mortality of surgical critically ill patients: A retrospective cohort study. Medicine. 2019;98(26).

40. Krpata DM, Keller DS, Samia H, Lawrence J, Obokhare I, Marderstein E, et al. Evaluation of inflammatory markers as predictors of hospital stay and unplanned readmission after colorectal surgery. Polish Journal of Surgery. 2013;85(4):198-203.

41. Lee JG, Kim YS, Lee YJ, Ahn HY, Kim M, Kim M, et al. Effect of Immune-Enhancing Enteral Nutrition Enriched with or without Beta-Glucan on Immunomodulation in Critically Ill Patients. Nutrients. 2016;8(6):336.

Table 1: Nutritional content of standard enteral formula and low-inflammatory index formula after the mixture.

\begin{tabular}{|c|c|c|c|c|c|}
\hline $\begin{array}{l}\text { Nutritional } \\
\text { information }\end{array}$ & $\begin{array}{l}\text { Low } \\
\text { inflammatory } \\
\text { index Formula } \\
\text { Per } 100 \mathrm{ml}\end{array}$ & $\begin{array}{l}\text { Standard } \\
\text { Formula Per } \\
100 \mathrm{ml}\end{array}$ & $\begin{array}{l}\text { Nutritional } \\
\text { information }\end{array}$ & $\begin{array}{l}\text { Low } \\
\text { inflammatory } \\
\text { index Formula } \\
\text { Per } 100 \mathrm{ml}\end{array}$ & $\begin{array}{l}\text { Standard } \\
\text { Formula Per } \\
100 \mathrm{ml}\end{array}$ \\
\hline $\begin{array}{l}\text { Total DII } \\
\text { score }\end{array}$ & -3.75 & -2.69 & Vitamin B12 & $0.53 \mathrm{mcg}$ & $0.53 \mathrm{mcg}$ \\
\hline Energy & 100 Kcal & 100 Kcal & & & \\
\hline Protein & $3.5 \mathrm{gr}$ & $3.5 \mathrm{gr}$ & Sodium & $98.6 \mathrm{~g}$ & $98.6 \mathrm{mg}$ \\
\hline Carbohydrate & $14.16 \mathrm{gr}$ & $14.16 \mathrm{gr}$ & Potassium & $142.4 \mathrm{~g}$ & $142.4 \mathrm{mg}$ \\
\hline Fiber & $0.44 \mathrm{gr}$ & $0.44 \mathrm{gr}$ & Calcium & $55 \mathrm{mg}$ & $55 \mathrm{mg}$ \\
\hline Total Fat & $3.5 \mathrm{gr}$ & $3.5 \mathrm{gr}$ & Magnesium & $27 \mathrm{mg}$ & $23.7 \mathrm{mg}$ \\
\hline Vitamin A & $100 \mathrm{mcg}$ & $63.69 \mathrm{mcg}$ & Chloride & $83.26 \mathrm{~g}$ & $83.26 \mathrm{mg}$ \\
\hline Vitamin E & $10 \mathrm{mg}$ & $1.13 \mathrm{mg}$ & Phosphors & $52.4 \mathrm{mg}$ & $52.4 \mathrm{mg}$ \\
\hline Vitamin $\mathrm{D}_{3}$ & $1.66 \mathrm{mcg}$ & $0.5 \mathrm{mcg}$ & Iron & $0.93 \mathrm{mg}$ & $0.93 \mathrm{mg}$ \\
\hline Vitamin K1 & $6.53 \mathrm{mcg}$ & $6.53 \mathrm{mcg}$ & Zinc & $1.34 \mathrm{mg}$ & $0.92 \mathrm{mg}$ \\
\hline Vitamin C & $66.66 \mathrm{mg}$ & $9.55 \mathrm{mg}$ & Copper & $90 \mathrm{mcg}$ & $90 \mathrm{mcg}$ \\
\hline Vitamin $B_{1}$ & $0.33 \mathrm{mg}$ & $0.15 \mathrm{mg}$ & Manganese & $0.13 \mathrm{mg}$ & $0.13 \mathrm{mg}$ \\
\hline Vitamin $B_{2}$ & $0.67 \mathrm{mg}$ & $0.18 \mathrm{mg}$ & Iodine & 9.53 & $9.53 \mathrm{mcg}$ \\
\hline Niacin & $2 \mathrm{mg}$ & $1.25 \mathrm{mg}$ & Chromium & $1.93 \mathrm{mcg}$ & $1.93 \mathrm{mcg}$ \\
\hline $\begin{array}{l}\text { Pantothenic } \\
\text { Acid }\end{array}$ & $0.66 \mathrm{mg}$ & $0.66 \mathrm{mg}$ & Fluoride & $0.2 \mathrm{mg}$ & $0.2 \mathrm{mg}$ \\
\hline Vitamin $B_{6}$ & $0.34 \mathrm{mg}$ & $0.13 \mathrm{mg}$ & Selenium & $13.3 \mathrm{mcg}$ & $3.5 \mathrm{mcg}$ \\
\hline Biotin & $15.9 \mathrm{mcg}$ & $15.9 \mathrm{mcg}$ & Turmeric & $0.1 \mathrm{gr}$ & 0 \\
\hline Folic Acid & $33.33 \mathrm{mcg}$ & $25.5 \mathrm{mcg}$ & Saffron & $0.02 \mathrm{gr}$ & 0 \\
\hline
\end{tabular}

Table 2: Source of added nutrients to standard formula

\begin{tabular}{ll}
\hline Nutrients & Company \\
\hline Retinyl acetate & Sigma \\
Ascorbic acid & Merck
\end{tabular}




\begin{tabular}{ll}
\hline Nutrients & Company \\
\hline Tocopherol acetate & Sigma \\
Cholecalciferol & Sigma \\
Thiamine hydrochloride & Sigma \\
Riboflavin & Sigma \\
Nicotinic acid & Sigma \\
Pyridoxine hydrochloride & Sigma \\
Folic acid & Sigma \\
Magnesium oxide & Merck \\
Zinc sulfate & Merck \\
Sodium selenite & Merck \\
\hline
\end{tabular}

Randomized \& Gradual Selection of Eligible Patients

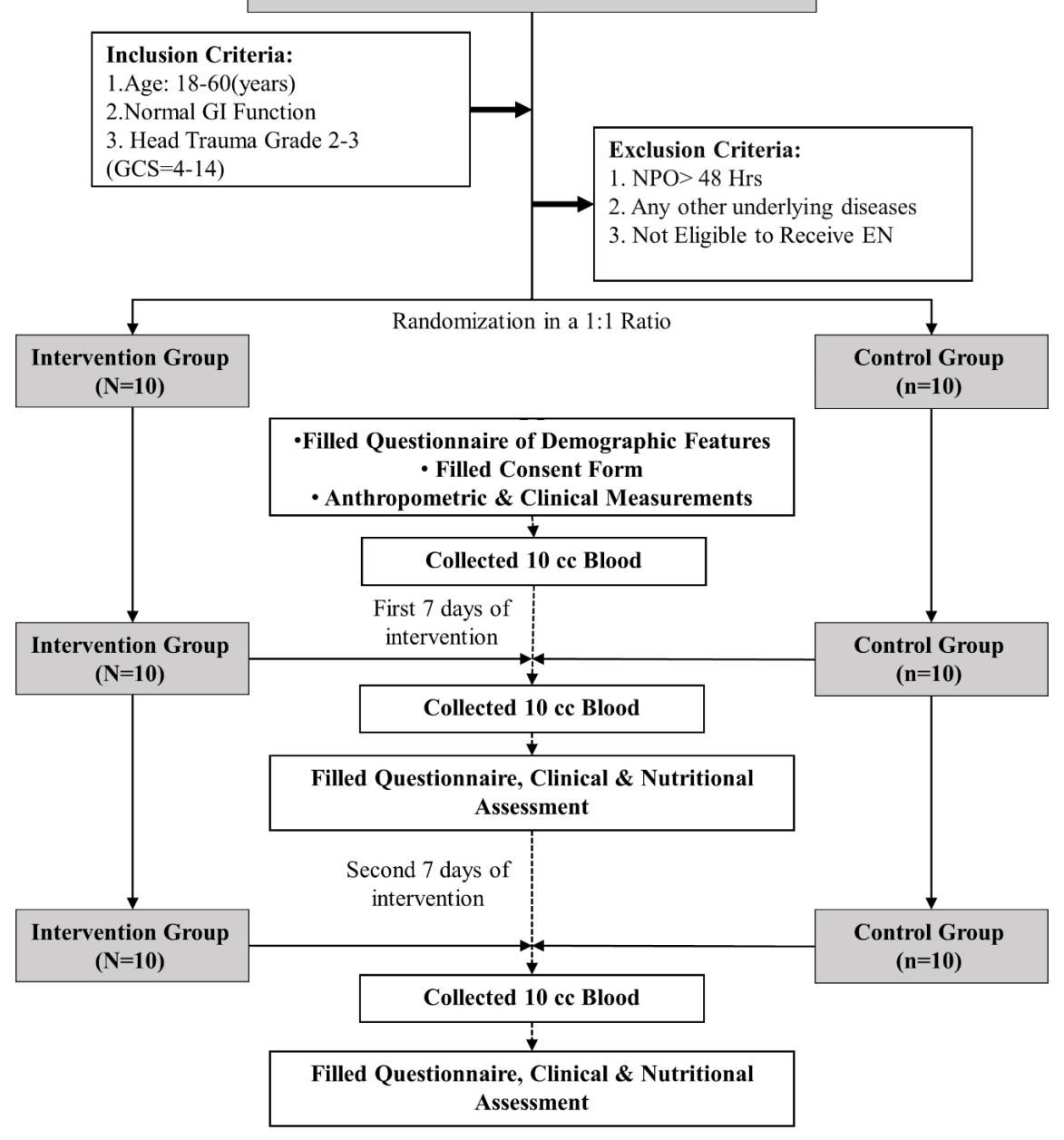

Figure 1: Intervention process flow chart

Table 3. Comparison of baseline clinical and nutritional characteristics between the trial groups

\begin{tabular}{llll}
\hline Variable & Intervention group Mean & Control group Mean \pm & P-value \\
& $\pm \mathrm{SD} N=10$ & $\mathrm{SD} N=10$ &
\end{tabular}




\begin{tabular}{|c|c|c|c|}
\hline Glasgow Coma Scale & $6.20 \pm 1.07$ & $6.20 \pm 1.32$ & 0.47 \\
\hline Oxygen saturation; \% & $95.62 \pm 2.88$ & $96.27 \pm 4.98$ & 0.72 \\
\hline Pulse Rate; bpm & $92.90 \pm 16.68$ & $89.80 \pm 15.84$ & 0.67 \\
\hline MAP; $\mathrm{mmHg}$ & $89.80 \pm 8.06$ & $97.7 \pm 9.36$ & 0.06 \\
\hline APACHE II & $13.90 \pm 2.42$ & $14.00 \pm 3.43$ & 0.94 \\
\hline SOFA & $6.30 \pm 1.57$ & $6.30 \pm 2.71$ & 0.99 \\
\hline SAPS II & $39.10 \pm 8.28$ & $36.30 \pm 11.86$ & 0.55 \\
\hline NUTRIC Score II & $3.50 \pm 0.97$ & $3.40 \pm 1.26$ & 0.84 \\
\hline MAC; $\mathrm{cm}$ & $27.60 \pm 2.45$ & $27.50 \pm 3.92$ & 0.95 \\
\hline $\begin{array}{l}\text { Energy Expenditure; } \\
\text { Kcal }\end{array}$ & $1925.00 \pm 272.08$ & $1920.00 \pm 278.09$ & 0.97 \\
\hline Abbreviation. GCS: & Abbreviation. GCS: & Abbreviation. GCS: & Abbreviation. GCS: \\
\hline $\begin{array}{l}\text { Glasgow Coma Scale; } \\
\text { bpm: beats per minute; }\end{array}$ & $\begin{array}{l}\text { Glasgow Coma Scale; } \\
\text { bpm: beats per minute; }\end{array}$ & $\begin{array}{l}\text { Glasgow Coma Scale; } \\
\text { bpm: beats per minute; }\end{array}$ & $\begin{array}{l}\text { Glasgow Coma Scale; } \\
\text { bpm: beats per minute; }\end{array}$ \\
\hline MAP: Mean Arterial & MAP: Mean Arterial & MAP: Mean Arterial & MAP: Mean Arterial \\
\hline Pressure; NUTRIC: & Pressure; NUTRIC: & Pressure; NUTRIC: & Pressure; NUTRIC: \\
\hline Nutrition Risk in & Nutrition Risk in & Nutrition Risk in & Nutrition Risk in \\
\hline Critically ill, APACHE: & Critically ill, APACHE: & Critically ill, APACHE: & Critically ill, APACHE: \\
\hline Acute Physiology And & Acute Physiology And & Acute Physiology And & Acute Physiology And \\
\hline Chronic Health & Chronic Health & Chronic Health & Chronic Health \\
\hline Evaluation, SOFA: & Evaluation, SOFA: & Evaluation, SOFA: & Evaluation, SOFA: \\
\hline Sequential Organ & Sequential Organ & Sequential Organ & Sequential Organ \\
\hline $\begin{array}{l}\text { Failure Assessment, } \\
\text { SAPS: Simplified Acute }\end{array}$ & $\begin{array}{l}\text { Failure Assessment, } \\
\text { SAPS: Simplified Acute }\end{array}$ & $\begin{array}{l}\text { Failure Assessment, } \\
\text { SAPS: Simplified Acute }\end{array}$ & $\begin{array}{l}\text { Failure Assessment, } \\
\text { SAPS: Simplified Acute }\end{array}$ \\
\hline Physiology Score, & Physiology Score, & Physiology Score, & Physiology Score, \\
\hline MAC: Mid Arm & MAC: Mid Arm & MAC: Mid Arm & MAC: Mid Arm \\
\hline $\begin{array}{l}\text { Circumference Data are } \\
\text { presented as mean } \pm \\
\text { standard deviation. }+\end{array}$ & $\begin{array}{l}\text { Circumference Data are } \\
\text { presented as mean } \pm \\
\text { standard deviation. }+\end{array}$ & $\begin{array}{l}\text { Circumference Data are } \\
\text { presented as mean } \pm \\
\text { standard deviation. }+\end{array}$ & $\begin{array}{l}\text { Circumference Data are } \\
\text { presented as mean } \pm \\
\text { standard deviation. }+\end{array}$ \\
\hline P-values were obtained & P-values were obtained & P-values were obtained & P-values were obtained \\
\hline $\begin{array}{l}\text { from independent } \\
\text { sample t-test. }\end{array}$ & $\begin{array}{l}\text { from independent } \\
\text { sample t-test. }\end{array}$ & $\begin{array}{l}\text { from independent } \\
\text { sample t-test. }\end{array}$ & $\begin{array}{l}\text { from independent } \\
\text { sample t-test. }\end{array}$ \\
\hline
\end{tabular}

Table 4. Comparison of baseline laboratory parameters between the trial groups

\begin{tabular}{llll}
\hline Variable & $\begin{array}{l}\text { Intervention group Mean } \\
\pm \mathrm{SD} N=10\end{array}$ & $\begin{array}{l}\text { Control group Mean } \pm \\
\text { SD } N=10\end{array}$ & P-value \\
Albumin; g/dL & $3.7 \pm 0.43$ & $3.6 \pm 0.43$ & \\
Total Protein; g/dL & $5.97 \pm 0.84$ & $5.87 \pm 0.49$ & 0.61 \\
Albumin/Total Protein & $0.62 \pm 0.060$ & $0.61 \pm 0.064$ & 0.75 \\
TNF- $\alpha$ & $5.81 \pm 2.38$ & $5.96 \pm 2.87$ & 0.72 \\
hs-CRP; mg/dL & $18.15 \pm 1.29$ & $17.58 \pm 1.32$ & 0.90 \\
Fasting Blood Sugar; & $136.9 \pm 35.40$ & $145.5 \pm 32.63$ & 0.34 \\
mg/dL & & & 0.58 \\
Total Cholesterol; & $112.1 \pm 36.60$ & $128.60 \pm 42.74$ & \\
mg/dL & & & 0.36 \\
LDL-c; mg/dL & $70.60 \pm 32.85$ & $69.30 \pm 34.18$ & 0.93 \\
HDL-c; mg/dL & $32.90 \pm 12.45$ & $35.4 \pm 3.62$ & 0.55 \\
Triglyceride; mg/dL & $105.5[91.5-119.6]$ & $92.5[82.8-136.4]$ & $0.88^{*}$ \\
AST; IU/L & $67.5[38-103.2]$ & $88[54.1-110]$ & $0.82^{*}$ \\
ALT; IU/L & $37.5[29.6-65.9]$ & $39.5[32.6-52.9]$ & $0.91^{*}$ \\
& & &
\end{tabular}




\begin{tabular}{|c|c|c|c|}
\hline ALP; IU/L & $157[143.2-199.4]$ & $157[150-164.6]$ & $0.99^{*}$ \\
\hline D-Bil; mg/dL & $0.305[0.278-0.485]$ & $0.275[0.233-0.320]$ & $0.71^{*}$ \\
\hline T-Bil; mg/dL & $0.880[0.800-1.045]$ & $1.165[1.000-1.300]$ & $0.08^{*}$ \\
\hline BUN; mg/dL & $35.7 \pm 8.33$ & $39.1 \pm 13.19$ & 0.49 \\
\hline Creatinine; mg/dL & $0.962 \pm 0.204$ & $0.974 \pm 0.216$ & 0.90 \\
\hline WBC; $(\times 1000 / \mu \mathrm{l})$ & $16.93 \pm 9.16$ & $11.84 \pm 4.58$ & 0.13 \\
\hline PLT; $(\times 1000 / \mu \mathrm{l})$ & $182 \pm 61$ & $178 \pm 55$ & 0.86 \\
\hline Abbreviation. TNF- $\alpha$ : & Abbreviation. TNF- $\alpha$ : & Abbreviation. TNF- $\alpha$ : & Abbreviation. TNF- $\alpha$ : \\
\hline $\begin{array}{l}\text { Tumor Necrosis Factor- } \\
\text { alpha, hs-CRP: high } \\
\text { sensitivity C- Reactive }\end{array}$ & $\begin{array}{l}\text { Tumor Necrosis Factor- } \\
\text { alpha, hs-CRP: high } \\
\text { sensitivity C- Reactive }\end{array}$ & $\begin{array}{l}\text { Tumor Necrosis Factor- } \\
\text { alpha, hs-CRP: high } \\
\text { sensitivity C- Reactive }\end{array}$ & $\begin{array}{l}\text { Tumor Necrosis Factor- } \\
\text { alpha, hs-CRP: high } \\
\text { sensitivity C- Reactive }\end{array}$ \\
\hline Protein, LDL-c: & Protein, LDL-c: & Protein, LDL-c: & Protein, LDL-c: \\
\hline Low-Density & Low-Density & Low-Density & Low-Density \\
\hline $\begin{array}{l}\text { Lipoprotein cholesterol; } \\
\text { HDL-c: High-Density }\end{array}$ & $\begin{array}{l}\text { Lipoprotein cholesterol; } \\
\text { HDL-c: High-Density }\end{array}$ & $\begin{array}{l}\text { Lipoprotein cholesterol; } \\
\text { HDL-c: High-Density }\end{array}$ & $\begin{array}{l}\text { Lipoprotein cholesterol; } \\
\text { HDL-c: High-Density }\end{array}$ \\
\hline $\begin{array}{l}\text { Lipoprotein cholesterol; } \\
\text { AST: Aspartate }\end{array}$ & Lipoprotein cholesterol; & $\begin{array}{l}\text { Lipoprotein cholesterol; } \\
\text { AST: Aspartate }\end{array}$ & Lipoprotein cholesterol; \\
\hline Aminotransferase, & Aminotransferase, & Aminotransferase, & Aminotransferase, \\
\hline ALT: Alanine & ALT: Alanine & ALT: Alanine & ALT: Alanine \\
\hline Aminotransferase, & Aminotransferase, & Aminotransferase, & Aminotransferase, \\
\hline ALP: Alkaline & ALP: Alkaline & ALP: Alkaline & ALP: Alkaline \\
\hline Phosphatase, T-Bil: & Phosphatase, T-Bil: & Phosphatase, T-Bil: & Phosphatase, T-Bil: \\
\hline Total Bilirubin, D-Bil: & Total Bilirubin, D-Bil: & Total Bilirubin, D-Bil: & Total Bilirubin, D-Bil: \\
\hline Direct Bilirubin, BUN: & Direct Bilirubin, BUN: & Direct Bilirubin, BUN: & Direct Bilirubin, BUN: \\
\hline Blood Urea Nitrogen. & Blood Urea Nitrogen. & Blood Urea Nitrogen. & Blood Urea Nitrogen. \\
\hline $\begin{array}{l}\text { Data are presented as } \\
\text { mean } \pm \text { standard }\end{array}$ & $\begin{array}{l}\text { Data are presented as } \\
\text { mean } \pm \text { standard }\end{array}$ & $\begin{array}{l}\text { Data are presented as } \\
\text { mean } \pm \text { standard }\end{array}$ & $\begin{array}{l}\text { Data are presented as } \\
\text { mean } \pm \text { standard }\end{array}$ \\
\hline deviation or median & deviation or median & deviation or median & deviation or median \\
\hline [interquartile range]. + & [interquartile range]. + & [interquartile range]. + & [interquartile range]. + \\
\hline P-values were obtained & $\mathrm{P}$-values were obtained & P-values were obtained & $\mathrm{P}$-values were obtained \\
\hline from independent & from independent & from independent & from independent \\
\hline sample t-test, unless & sample t-test, unless & sample t-test, unless & sample t-test, unless \\
\hline otherwise indicated. & otherwise indicated. & otherwise indicated. & otherwise indicated. \\
\hline${ }^{*} \mathrm{P}$-values were & ${ }^{*} \mathrm{P}$-values were & ${ }^{*} \mathrm{P}$-values were & ${ }^{*} \mathrm{P}$-values were \\
\hline obtained from & obtained from & obtained from & obtained from \\
\hline Mann-Whitney U test. & Mann-Whitney U test. & Mann-Whitney U test. & Mann-Whitney U test. \\
\hline
\end{tabular}



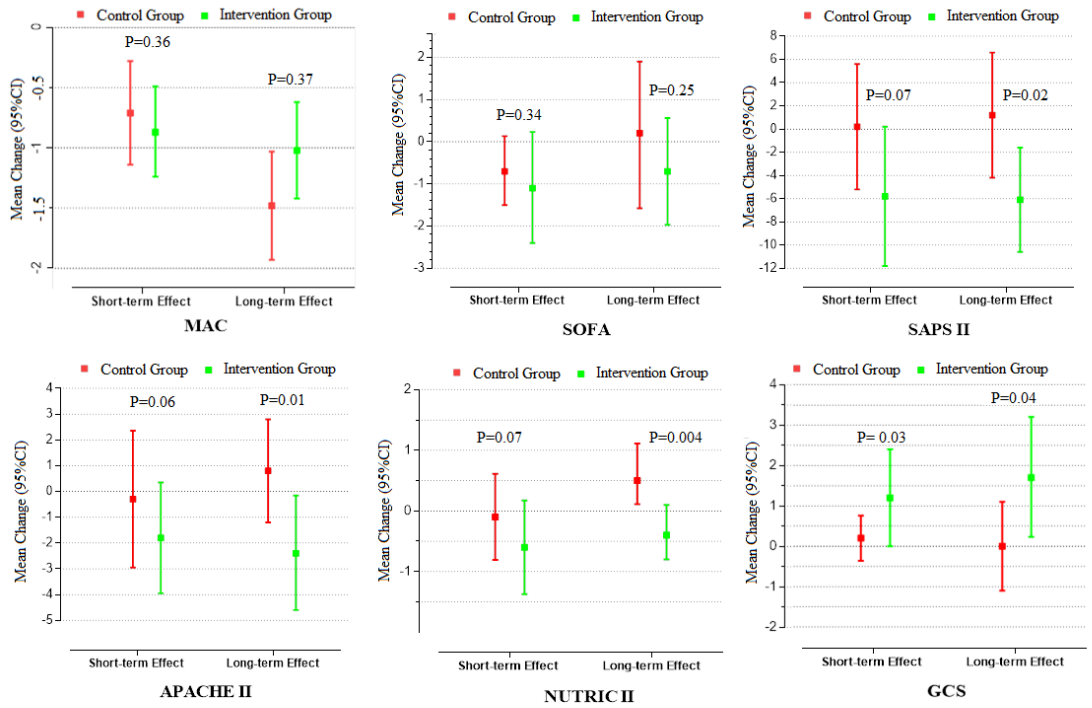

Figure 2. Adjusted mean change in biochemical factors from baseline to 1-week (Short-tem) and 2-week (Long-term) follow-up.

Figure 2. Age and sex-adjusted mean change for biochemical factors in the intervention group $(\mathrm{N}=10)$ and control group $(\mathrm{N}=10)$ from baseline to 1-week (short-term) and 2-week (long-term) follow-up. Abbreviation. MAC: Mid Arm Circumference; SOFA: Sequential Organ Failure Assessment; SAPS: Simplified Acute Physiology; APACHE: Acute Physiology And Chronic Health Evaluation; NUTRIC score II: Nutrition Risk in Critically ill score II; GCS: Glasgow Coma Scale

\begin{tabular}{|c|c|c|c|c|c|c|}
\hline $\begin{array}{l}\text { Table } \mathbf{5 .} \\
\text { Adjusted } \\
\text { mean change } \\
\text { in }\end{array}$ & $\begin{array}{l}\text { Table } \mathbf{5 .} \\
\text { Adjusted } \\
\text { mean change } \\
\text { in }\end{array}$ & $\begin{array}{l}\text { Table } \mathbf{5 .} \\
\text { Adjusted } \\
\text { mean change } \\
\text { in }\end{array}$ & $\begin{array}{l}\text { Table } \mathbf{5 .} \\
\text { Adjusted } \\
\text { mean change } \\
\text { in }\end{array}$ & $\begin{array}{l}\text { Table } \mathbf{5} . \\
\text { Adjusted } \\
\text { mean change } \\
\text { in }\end{array}$ & $\begin{array}{l}\text { Table } \mathbf{5} . \\
\text { Adjusted } \\
\text { mean change } \\
\text { in }\end{array}$ & $\begin{array}{l}\text { Table } \mathbf{5} . \\
\text { Adjusted } \\
\text { mean change } \\
\text { in }\end{array}$ \\
\hline biochemical & biochemical & biochemical & biochemical & biochemical & biochemical & biochemical \\
\hline factors from & factors from & factors from & factors from & factors from & factors from & factors from \\
\hline baseline to & baseline to & baseline to & baseline to & baseline to & baseline to & baseline to \\
\hline 1-week and & 1-week and & 1-week and & 1-week and & 1-week and & 1-week and & 1-week and \\
\hline 2-week & 2-week & 2-week & 2-week & 2-week & 2 -week & 2 -week \\
\hline follow-up. & follow-up. & follow-up. & follow-up. & follow-up. & follow-up. & follow-up. \\
\hline Vari & $\begin{array}{l}\text { Short-term } \\
\text { change }\end{array}$ & $\begin{array}{l}\text { Short-term } \\
\text { change }\end{array}$ & $\begin{array}{l}\text { Short-term } \\
\text { change }\end{array}$ & $\begin{array}{l}\text { Long-term } \\
\text { change }\end{array}$ & $\begin{array}{l}\text { Long-term } \\
\text { change }\end{array}$ & $\begin{array}{l}\text { Long-term } \\
\text { change }\end{array}$ \\
\hline & $\begin{array}{l}\text { Intervention } \\
N=10\end{array}$ & Control $N=10$ & Effect Size & $\begin{array}{l}\text { Intervention } \\
N=10\end{array}$ & Control $N=10$ & Effect Size \\
\hline TNF_ $\alpha$ & $\begin{array}{l}0.78(-0.86, \\
2.42)\end{array}$ & $\begin{array}{l}1.02(-0.62, \\
2.66)\end{array}$ & $\begin{array}{l}-0.23(-2.63, \\
2.16)\end{array}$ & $\begin{array}{l}1.10(-0.91, \\
3.11)\end{array}$ & $\begin{array}{l}2.03(0.03, \\
4.04)+\end{array}$ & $\begin{array}{l}-0.93(-3.86 \\
1.99)\end{array}$ \\
\hline $\begin{array}{l}\text { hs-CRP; } \\
\mathrm{mg} / \mathrm{dL}\end{array}$ & $\begin{array}{l}-1.39(-2.47 \\
-0.32)+\end{array}$ & $\begin{array}{l}-0.13(-1.21, \\
0.94)\end{array}$ & $\begin{array}{l}-1.26(-2.83, \\
0.30)\end{array}$ & $\begin{array}{l}-2.73(-3.67, \\
-1.79)+\end{array}$ & $\begin{array}{l}0.65(-0.29, \\
1.58)\end{array}$ & $\begin{array}{l}-3.37(-4.73 \\
-2.01)+\end{array}$ \\
\hline Alb; gr/dL & $\begin{array}{l}0.01(-0.15 \\
0.16)\end{array}$ & $\begin{array}{l}0.04(-0.11, \\
0.19)\end{array}$ & $\begin{array}{l}-0.03(-0.26 \\
0.19)\end{array}$ & $\begin{array}{l}-0.03(-0.22, \\
0.17)\end{array}$ & $\begin{array}{l}-0.09(-0.29, \\
0.10)\end{array}$ & $\begin{array}{l}0.07(-0.22, \\
0.35)\end{array}$ \\
\hline TP; gr/dL & $\begin{array}{l}0.19(-0.30, \\
0.68)\end{array}$ & $\begin{array}{l}0.21(-0.28 \\
0.70)\end{array}$ & $\begin{array}{l}-0.02(-0.74, \\
0.69)\end{array}$ & $\begin{array}{l}0.33(-0.27, \\
0.92)\end{array}$ & $\begin{array}{l}0.17(-0.43, \\
0.77)\end{array}$ & $\begin{array}{l}0.16(-0.71, \\
1.03)\end{array}$ \\
\hline $\begin{array}{l}\text { Alb:TP } \\
\text { Ratio }\end{array}$ & $\begin{array}{l}-0.022 \\
(-0.07,0.02)\end{array}$ & $\begin{array}{l}-0.013 \\
(-0.06,0.03)\end{array}$ & $\begin{array}{l}-0.01(-0.08, \\
0.06)\end{array}$ & $\begin{array}{l}-0.04(-0.09, \\
0.01)\end{array}$ & $\begin{array}{l}-0.03(-0.08, \\
0.02)\end{array}$ & $\begin{array}{l}0.01(-0.09, \\
0.07)\end{array}$ \\
\hline
\end{tabular}




\begin{tabular}{|c|c|c|c|c|c|c|}
\hline $\mathrm{FBS} ; \mathrm{mg} / \mathrm{dL}$ & $\begin{array}{l}-13.8 \\
(-58.63 \\
30.91)\end{array}$ & $\begin{array}{l}-21.3 \\
(-66.01 \\
23.51)\end{array}$ & $\begin{array}{l}7.5(-57.70 \\
72.52)\end{array}$ & $\begin{array}{l}-41.7 \\
(-51.74 \\
-31.6)+\end{array}$ & $\begin{array}{l}-22.9 \\
(-32.61 \\
-13.3)+\end{array}$ & $\begin{array}{l}-18.7 \\
(-32.86 \\
-4.64)+\end{array}$ \\
\hline $\mathrm{TC} ; \mathrm{mg} / \mathrm{dL}$ & $\begin{array}{l}26.51(5.64 \\
47.57)+\end{array}$ & $\begin{array}{l}59.7(38.80 \\
80.63)+\end{array}$ & $\begin{array}{l}-33.2(-60.6 \\
0.87)\end{array}$ & $\begin{array}{l}16.8(-2.62, \\
36.30)\end{array}$ & $\begin{array}{l}42.9(23.51 \\
62.44)\end{array}$ & $\begin{array}{l}-26.2 \\
(-54.43 \\
2.14)\end{array}$ \\
\hline $\begin{array}{l}\text { LDL-c; } \\
\mathrm{mg} / \mathrm{dL}\end{array}$ & $\begin{array}{l}10.1(-11.42, \\
31.62)\end{array}$ & $\begin{array}{l}36.9(16.18 \\
57.63)+\end{array}$ & $\begin{array}{l}-26.8 \\
(-57.05 \\
3.43)\end{array}$ & $\begin{array}{l}2.1(-16.08 \\
20.29)\end{array}$ & $\begin{array}{l}35.8(17.60 \\
53.98)+\end{array}$ & $\begin{array}{l}-33.7 \\
(-60.16 \\
-7.21)+\end{array}$ \\
\hline $\begin{array}{l}\text { HDL-c; } \\
\text { mg/dL }\end{array}$ & $\begin{array}{l}0.24(-6.83 \\
7.30)\end{array}$ & $\begin{array}{l}1.76(-5.31 \\
8.83)\end{array}$ & $\begin{array}{l}-1.52 \\
(-11.81 \\
8.76)\end{array}$ & $\begin{array}{l}-1.78(-8.52 \\
4.96)\end{array}$ & $\begin{array}{l}0.88(-5.86 \\
7.63)\end{array}$ & $\begin{array}{l}-2.67 \\
(-12.48 \\
7.14)\end{array}$ \\
\hline TG; mg/dL & $\begin{array}{l}52.1(-25.78 \\
129.99)\end{array}$ & $\begin{array}{l}55.4(-22.49 \\
133.28)\end{array}$ & $\begin{array}{l}-3.3(-116.6 \\
110.1)\end{array}$ & $\begin{array}{l}43.4(-33.54 \\
120.32)\end{array}$ & $\begin{array}{l}32.61 \\
(-44.32, \\
109.5)\end{array}$ & $\begin{array}{l}10.78 \\
(-101.2, \\
122.7)\end{array}$ \\
\hline ALT; IU/L & $\begin{array}{l}47.5(-89.1 \\
184.13)\end{array}$ & $\begin{array}{l}55.3(-81.25 \\
191.94)\end{array}$ & $\begin{array}{l}-7.81 \\
(-206.6,191)\end{array}$ & $\begin{array}{l}54.2(- \\
39.44,147.9)\end{array}$ & $\begin{array}{l}37.6(-55.98, \\
131.32)\end{array}$ & $\begin{array}{l}16.54 \\
(-119.7 \\
152.8)\end{array}$ \\
\hline ALP; IU/L & $\begin{array}{l}54.2(-39.44 \\
147.9)\end{array}$ & $\begin{array}{l}37.7(-55.9 \\
131.3)\end{array}$ & $\begin{array}{l}16.5(-119.7 \\
152.8)\end{array}$ & $\begin{array}{l}144.9 \\
257.4)\end{array}$ & $\begin{array}{l}280.8(168.4, \\
393.3)\end{array}$ & $\begin{array}{l}-135.9 \\
(-299.5 \\
27.7)\end{array}$ \\
\hline $\begin{array}{l}\text { D-Bil; } \\
\text { mg/dL }\end{array}$ & $\begin{array}{l}0.015(-1.10 \\
1.13)\end{array}$ & $\begin{array}{l}-0.88(-1.99 \\
0.23)\end{array}$ & $\begin{array}{l}0.89(-0.72, \\
2.52)\end{array}$ & $\begin{array}{l}0.032(-1.21 \\
1.27)\end{array}$ & $\begin{array}{l}-1.01(-2.25 \\
0.23)\end{array}$ & $\begin{array}{l}1.04(-0.76, \\
2.85)\end{array}$ \\
\hline $\begin{array}{l}\text { T-Bil; } \\
\text { mg/dL }\end{array}$ & $\begin{array}{l}-0.053 \\
(-1.41,1.31)\end{array}$ & $\begin{array}{l}-1.06(-2.42 \\
0.29)\end{array}$ & $\begin{array}{l}1.01(-0.97 \\
2.99)\end{array}$ & $\begin{array}{l}-0.084 \\
(-1.49,1.32)\end{array}$ & $\begin{array}{l}-1.18(-2.58 \\
0.22)\end{array}$ & $\begin{array}{l}1.10(-0.94 \\
3.14)\end{array}$ \\
\hline $\begin{array}{l}\text { PLT; } \\
(\times 1000 / \mu l)\end{array}$ & $\begin{array}{l}102.8(31.26 \\
174.3)+\end{array}$ & $\begin{array}{l}91.68(20.14 \\
163.2)+\end{array}$ & $\begin{array}{l}11.13 \\
(-92.99 \\
115.2)\end{array}$ & $\begin{array}{l}207.6(78.15 \\
337.1)+\end{array}$ & $\begin{array}{l}219.8(90.3 \\
349.2)+\end{array}$ & $\begin{array}{l}-12.1 \\
(-200.5, \\
176.2)\end{array}$ \\
\hline
\end{tabular}




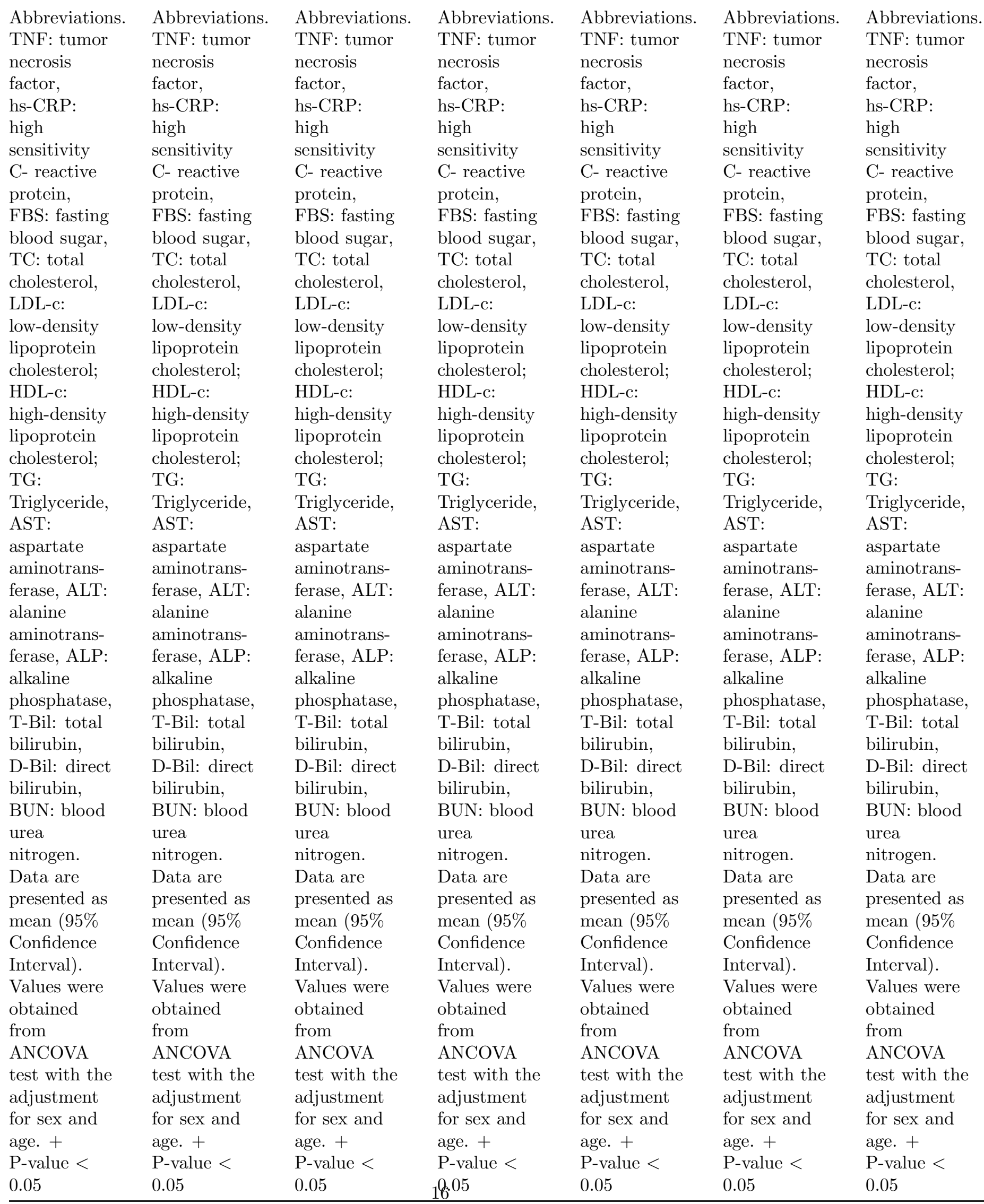


Figure 3. Comparison of length of hospital stay between the intervention group $(\mathrm{N}=10)$ and control group $(\mathrm{N}=10)$.

Values were obtained from the Analysis of Covariance (ANCOVA) test with the adjustment for sex and age. 